\title{
Sad Fetus Syndrome - Gestational Trophoblastic Disease Concurrent with a Living Fetus or Fetuses
}

\author{
W. Malinowski ${ }^{1}$, I. Biskup ${ }^{2}$, W. Dec ${ }^{3}$ \\ ${ }^{1}$ Kutno Hospital, Kutno, Poland; ${ }^{2}$ Kufstein Hospital, Kufstein, Austria; ${ }^{3}$ Lodz University \\ Hospital, Lodz, Poland
}

\begin{abstract}
The term gestational trophoblastic disease is used to indicate a group of both benign and malignant trophoblast, including molar degeneration of villi, hydatid mole, invasive mole and choriocarcinoma.

This study shows a new classification of trophoblastic disease existing with a living fetus or fetuses. Benign hydatid mole is the initial stage of the disease continuum, whereas highly malignant choriocarcinoma is the final stage of this spectrum.
\end{abstract}

Key words: Choriocarcinoma, Gestation, Mola hydatidosa, Pregnancy, Trophoblastic disease, Sad fetus syndrome

\section{INTRODUCTION}

It is a very sad situation when a fetus is co-existing with mola or choriocarcinoma, because of a very bad prognosis. This is why in such cases we called it: "Sad Fetus Syndrome".

Gestational trophoblastic disease is not a uniform condition. It includes a whole group of both benign and malignant neoplasms of trophoblast.

These include: molar degeneration of villi, hydatid mole, invasive mole and choriocarcinoma.

Benign hydatid mole is the initial stage of the disease continuum, whereas highly malignant choriocarcinoma is the final stage of this spectrum [26].

In 1976, two forms of hydatid mole were recognized: complete mole and partial mole [65]. It is clinically essential to differentiate them precisely. The risk of developing choriocarcinoma when a pregnancy is complicated by complete mole is 2.000 to 4.000 times higher than when a delivery or miscarriage is not complicated [10]. Yet, there is more and more evidence that partial mole does not incur such a risk [66].

Hyperplasia and neoplasms of trophoblast are more often encountered in multifetal pregnancies [36]. They appear 6 or 7 times often than one might expect in pregnancies 


\section{W. Malinowski et al.}

preceded by a twin delivery [15]. What is rare, but essential for the gestation development, is when the trophoblastic disease is concomitant with a fetus or fetuses that develop normally. This concurrence happens in 1:14.000 to $1: 100.000$ gestations, and in $1: 26$ of all trophoblast hyperplasia and neoplasm cases $[6,30]$. A study suggests that the simultanously existence of this pathology with a fetus that is developing normally indicates that a multiple existed initially.

Such concurrence can have the form of:

1. large edematous changes within placenta/molar degeneration/concomitant with a fetus or fetuses of normal development;

2. complete hydatid mole concurrent with living fetus and normal placenta;

3. partial hydatid mole concurrent with living or dead fetus;

4. choriocarcinoma concurrent with fetus of normal development.

\section{Molar Degeneration of Villi [degeneratio hydatiosa Villi]}

This condition is encountered relatively often in placentas from miscarriages or pathological pregnancies [48]. Trophoblasts particularly often contain "empty" fetal ova. Macroscopically, degenerative changes of villi resemble hydatid mole. The stroma within the placenta is then clearly swollen in a grape-like form which results from increased fluid accumulation in the mesenchymal stroma. Microscopically, the villi are cyst-like dilated and the trophoblast proliferation is increased. Karyotyping the tissue affected by molar degeneration showed that the diploid chromosome complement was of $46, \mathrm{XX}$ or $46, \mathrm{XY}$ types. When the polymorphism of the length of DNA restrictive fragments was examined, the genetic material was found to have been of both parents' origin, and identical with that in the tissue in the healthy part of the placenta. Thus one can assume that the molar degeneration of villi which is concurrent with a living fetus does not result from a pregnancy which initially was multiple $[34,42]$.

Only a microscopic or genetic examination can differentiate molar degeneration from hydatid mole. Because of its small size and the presence of blood vessels, the degeneration does not influence really negatively the intrauterine development of fetuses which have not been injured by other factors. No malignant lesions have been found in such cases either.

\section{Complete Hydatld Mola [mola hydatiosa completa]}

This condition is the most commom form of hydatid mole. The world prevalence varies geographically. The rate in US is 1:1,200 gestations, in Japan 1:500, in Indonesia 1:100 $[49,56,70]$. Its concurrence with a living fetus happens much more rarely, and ranges from $1: 22.000$ to $1: 100.000$ [30].

The term "hydatid" dates back to the 6.th century AD and was then used by Aetius of Amida [acc. 43]. The $12^{\text {th }}$ century AD brings a legend which tells that Princess Margaret of Flanders supposedly delivered 365 children all at once.

182 of them were considered to be boys and given the name of John, 182 were girls and named Elizabeth. One "child" was believed to be a hermaphrodite and buried 
unchristened [acc. 50]. Although it is still unclear what is true in the legend, it is worth noticing that even in those times there was interest in the sex of a mole.

Contemporary reports which are based on cytogenetic examinations have revealed a diploid chromosome complement in complete mole tissue. In 90\% the karyotype was female $46, \mathrm{XX}$, and in $10 \%$ it was male $46, \mathrm{XY}$ [32]. The result is quite surprising since the ratio 1:1: should be more expected.

The studies based on the polymorphism analysis of chromosome DNA restrictive fragments' length [34, 40,42, 46], on HLA haplotyping [28, 37] and om enzyme polymorphism [69] have proved that all nuclear chromosomes in 46,XX and 46,XY sets are of paternal origin [androgenesis]. On the contrary, cytoplasmic DNA, present in mitochondria, is of maternal origin only [20,64].

If hydatid mole contains $46, \mathrm{XX}$ karyotype whose chromosomes are only of paternal origin, it is due to the duplication of haploid [23,X] genetic material which derives from a single spermatozoon [monospermia] [69]. The fact that there are no maternal chromosomes can be explained by the inactivation or lack of the nucleus in the egg cell. The pathogenesis of complete hydatid mole of the 46,XY karyotype is based on the fertilization of an "empty" non-nucleated egg cell by two spermatozoa at a time [dispermia] $[24,33,47,58]$. The survival of each cell depends on the fact if there is at least one chromosome $X$ in it. Thus the total lack of $46, Y Y$ karyotype in molar tissue could explain the inability of such a zygote to survive.

At present, only complete mole is believed to be able to transform malignantly. It refers to $15-20 \%$ of all cases $[14,58]$. Different mechanisms of complete hydatid mole pathogenesis [monospermia, dispermia] pose the question if the risk of choriocarcinoma development is connected with its zygote type. Data published so far $[14,58]$ suggest that it is the heterozygotic $[46, X Y]$ form of complete mole that transforms malignantly rather than its homozygotic $[46, X X]$ one.

The findings of genetic and cytogenetic studies presented in this paper suggest that the concurrence of complete mole with a living fetus results from a pregnancy which initially was multiple. It is impossible for a fetus of normal development to originate from a cell line containing only paternal genetic material. What also proves the dizygotism of such a pregnancy is that the karyotype of the tumour tissue and that of the normally developing fetus are different [23,34]. A group of experts discovered 46, XX karyotype in the complete hydatid molar tissue, whereas the normally developing fetus had $46, X Y$ karyotype. They also reviewed the relevant literature and found that in 46 twin and 1 triple pregnancies, all of which were complicated by complete mole, the sex of a normally developing fetus was male in 15 cases, female in 9 and in the other cases the sex of the newborns had not been mentioned.

Only 3 "triple" pregnancies where complete mole was concomitant with two normally developing fetuses have been described so far $[1,44,53]$. In all these cases multiple pregnancies resulted from ovulation stimulating therapy by means of klorifen and jumal menopausal gonadotropin. Such a stimulation triggers polyovulation but at the same time the risk of pathological, non-nucleated egg cells being created, which after fertilization develop in the form of complete mole. So far it is possible to explain only the pathogenesis of this phenomenon.

An important point in multiple pregnancies complicated by complete mole is how the pathologically changed trophoblast influences the course of the gestation and the prog- 
nosis for the developing fetus or fetuses. Such pregnancies usually terminate spontaneously in the 2nd trimester [1,4], and the survival rate of extremely premature infants is almost zero. Yet, there have been cases describing gestations which lasted over 31 weeks $[6,27,59]$. Despite the fact that these reports are not exhaustive, complete hydatid mole does not seem to have significantly negative influence on a normally developing fetus, excluding intrauteral hypotrophy and prematurity. What is worth noticing is the fact that in over half of the cases the placentas which developed normally and those molarly changed were implanted rather far away from each other. The course of gestation is sometimes complicated by early appearance of EPH gestosis. The symptoms may sometimes be so increasingly severe that gestation has to be terminated as early as before the 20 th week [34]. The perinatal period is often also complicated by higher bleeding from the uterine cavity.

After such a pregnancy, the patient needs to be routinely monitored for a malignant lesion, which can appear in such cases.

\section{Partial Hydatid Mole [mola hydatiosa partialis]}

Among pathologies of the fetal ovum, partial hydatid mole is relatively rare. Among trophoblast hyperplasia and neoplasms, it is observed in around $25 \%$ of cases [40]. It usually creates a focal lesion within the normal tissue of a placenta. Apart from tumour tissue, partial mole can be differentiated from complete mole by the presence of unchanged elements of fetus or afterbirth [31, 60]. The amount of such elements can vary considerably: from a microscopically undetectable fetus to a viable one. Here, a cytogenetic examination characteristically reveals a polyploid karyotype, usually in the form of $69, \mathrm{XX}$ or $69, \mathrm{XXY}$ triploidy $[40,61,62]$. 69,XXY karyotype has never been observed here $[29,40]$. This phenomenon can be explained by very weak proliferation of these cells. The impairment of their vitality, often leading to early miscarriages [3-4 weeks after conception] [9], could be responsible for the absence of the 69,XXY triploid chromosome set in partial mole. The fact that $69, \mathrm{XXY}$ karyotype predominates $69, \mathrm{XXX}$ more than one could expect, can also be explained by the impairment of conceptus development [40].

Genetic studies have proved that when the karyotype in partial mole is triploid, two genomes are generally of paternal and one of maternal origin $[38,40]$. Thus, dispermia seems to be the ethiological factor, i.e. a single egg cell being fertilized by two spermatozoa. The analysis of mitochondrion DNA has shown that both in partial and complete moles the cytoplasmic genetic material was only of maternal origin, as it happens in a normal result of conception [39].

In the literature there have been cases where in partial mole the karyotype was tetraploid, mosaicked [diploidy/tetraploidy] and even diploid [40, 54, 62]. Paternal material was prevalent everywhere there. In $92, \mathrm{XXXX}$ tetraploidy, there were 3 paternal and 1 maternal genomes. The probable ethiological machanism here was the fertilization of a single egg cell by 3 sprematozoa. In partial mole with a diploid karyotype, chromosomal DNA contained both parents' genetic material [40], but paternal material predominated. This suggests that two different cell populations are simultaneously present in the tumour tissue. This mole might have been initially a twin pregnancy. 
Animal experiments have highlighted that paternal and maternal genomes affect a developing conceptus differentlty $[5,57]$. The paternal genome stimulates the development of trophoblast, whereas the maternal one that of embryoblast. The results of the examinations can be used to explain the pathogenesis of various types of mole. In complete hydatid mole with a diploid, fully androgenetic chromosome set, trophoblast hyperplasia accompanies the lack of the development of embryonal tissue. On the other hand, in partial mole of triploid karyotype [ 2 paternal and 1 maternal sets] trophoblast hyperplasia is not as big and there are fewer elements of fetus and afterbirth present. It has been observed that when a double paternal genome was present, all triploid karyotype gestations had become molar, whereas when there were two maternal genomes, it referred to only $14 \%$ [17]. Malignant transformation also depends on how much paternal genomes predominate over maternal ones [40]. Unlike the trophoblast of normal gestation, androgenetic complete mole is the most vulnerable to such a change. Partial hydatid mole [ 2 paternal and 1 maternal sets] would be, then, of an intermediate risk. Consequently, both the morphological features of a mole and the risk of its transformation into choriocarcinoma depend on the paternal versus maternal genome ratio in a zygote.

The findings presented in this study suggest that in some cases partial mole concurrent with a living fetus may result from a pregnancy which was multiple initially. The presence of a triploid or tetraploid karyotype with a predominant paternal chromosome set excludes any possibility for a normal fetus to develop. Such a possibility would exist only if maternal genomes were predominant.

The prognosis for gestations of this kind is poor. Most of them terminate spontaneously in the $1^{\text {st }}$ trimester. It refers more often to the cases of $69, \mathrm{XXY}$ karyotype than those of $69, \mathrm{XXX}$. There has been a case [51] of twin pregnancy which was monochorial, diamniotic and complicated by partial mole, and which was nevertheless carried till the $3^{\text {rd }}$ trimester. The fetus with molar lesions in part of its placenta had a considerable retardation of the intrauterine growth and died before being born. Yet, the other fetus developed normally.

When pregnancies were complicated by partial mole with a diploid karyotype, serum HCG and AFP levels were considerably higher in pregnant women [21].

In case of partial mole, prognosis is very good. So far there is no convincing evidence which could confirm a malignant transformation. Once the afterbirth leaves a woman's body, the danger practically disappears. Yet, it does not mean that such a danger does not exist at all. One report [3] says that because of a persistingly increased HCG level during the puerperium, it was necessary to intervene therapeutically in 1:200 cases. Thus all patients after pregnancies complicated by partial mole have to be routinely folled-up.

\section{Choriocarcinoma}

It is an extremely malignant form of a trophoblast neoplasm. In most cases it appears after past complete hydatid mole, but it can also occur after miscarriage, normal labour or ectopic pregnancy.

A cytognetic analysis of choriocarcinoma tissue showed a diploid chromosome com- 
plement. What is surprising is a very high occurrence rate of $46, X Y$ heterozygotic type $[55,63]$. A genetic analysis based on determining the length of DNA restrictive fragments and antigens of HLA-DQ type proved that there was only paternal material in cancerous tissue $[25,46]$.

The concurrence of choriocarcinoma and a full-term, normally developed fetus is a rare phenomenon. So far there have been as few as some tens of such cases described $[7,8,11,12,18,19,22,35,41,45,52]$. The occurrence rate of such concomitance seems higher, but in many cases it is unrecognized. If there are no clinical symptoms of a trophoblast disease and at the same time the pregnancy develops normally, the physician does not assume there is such a pathology in process. A right diagnosis is even more difficult because the neoplastic focus is usually small in size and macroscopically very much resembles placental infarct, which is encountered fairly often. One has to believe that choriocarcinoma diagnosed after normal labour or miscarriage, at least in part of cases, existed in the time of gestation.

Choriocarcinoma, as it has been said before, in most cases is the continuum of complete hydatid mole. Thus, the presence of its focus in a full-term pregnancy placenta with a normally developing fetus suggests that the gestation was initially multiple. The peripheral localization in the placenta may also result from this course of the disease. Another explanation could be the transformation of partial hydatid mole into choriocarcinoma. Yet, contemporary cytogenetic studies do not confirm this concept. Another mechanism of the appearance of a neoplastic focus in a placenta can be its metastases from an activated latent form of cancer. There has been a case described of choriocarcinoma symptoms which appeared after the latency period as long as 10 years after the last pregnancy [2].

In most cases choriocarcinoma concomitant with a normal placenta and full-term fetus is undiagnosed during the pregnancy. Very often there are no symptoms of the disease then [52]. Non-metastatic forms of choriocarcinoma may not be revealed because after the delivery they leave the woman's body together with the afterbirth. In the perinatal period, choriocarcinoma metastases are sometimes diagnosed as embolia by amniotic fluid, DIC or thrombo-embolic disease. A postpartum macroscopic evaluation of each placenta lesion. In most cases cancerous foci are very small in size: from microscopic to $2-3 \mathrm{~cm}$ in diameter [11] and resemble common placental infarcts [52]. In such cases a right diagnosis is made only after a few months following the childbirth. Then clinical symptoms of the disease appear and they have the form of pathological bleeding from the genital tracts, and of lung, vagina, liver or brain metastases. Such delayed recognition worsens the prognosis considerably.

Some symptoms may suggest that a choriocarcinoma is developing in the placenta. This neoplasm is very invasive. Its development may lead to the damage of unchanged placental trophoblast and subsequently to a fetus-to-mother blood shunt. Depending on how big the damaged vessels and the damage itself are, the fetal exsanguination can be chronic or acute and massive, and can result in [19, 52]:

1. the presence of fetal blood cells in maternal blood circulation;

2. nonhemolytic anemia of fetus;

3. generalized edema of fetus;

4. sudden intrauterine death of fetus. 
Thus, in case of unexpected intrauterine death or unexplained anemia or generalized edema of a fetus, after the delivery the placenta must be carefully examined mascroscopically, and biopsy specimens from suspected regions taken for a histological examination. Examining fetal blood cell in pregnant women can also be helpful.

Macroscopically, a neoplastic lesion looks like a small white and grey region, resembling infarct; it may also resemble haemorrhagic nodules [11, 52] localized at the edge of a placenta [52]. In case of a chronic feto-maternal blood shut, the placentas after deliveries were described as pale, tumid, large, and their weight 800 to 1.300 grams [19].

All patients with choriocarcinoma "in situ" should be monitored after the childbirth. This helps to discover an early recurrence of the disease.

Choriocarcinoma can be dangerous to a concomitant living fetus for the following reasons $[11,52]$ :

1. pre-mature birth resulting from maternal complications caused by metastases;

2. fetus affected by severe anemia and generalized edema;

3. fetal necrosis caused by massive exsanguination into maternal circulatory system;

4. fetal necrosis or newborn's death caused by direct metastasis of the cancer.

Although metastatic choriocarcinoma in a newborn is observed very rarely, it should always be considered. Generally after the birth, there are no clinical symptoms which may suggest that the newborn suffers from the disease. They begin to appear between the $2^{\text {nd }}$ and $6^{\text {th }}$ month of an infant's life $[13,67]$. That is why all the children from gestations complicated by choriocarcinoma need to have HCG levels tested from the birth till the $6^{\text {th }}$ month of their lives.

As we have already mentioned trophoblast hyperplasia or neoplasm can be concurrent with a living fetus or fetuses. Thanks to placenta morphological examinations, 5 types of such coexistence have been distinguished [6]:

1. small, local vesiculiform degeneration of trophoblast, which develops in a single placenta and affects only one cotyledon;

2. multifocal vesiculiform degeneration in a single placenta;

3. almost complete degeneration of a single placenta which is in a common amniotic sac with a normally developing fetus;

4. massive molar lesion, but limited only to part of placenta;

5. molar changes affect one of two seperate placentas.

According to our study, numbers 4 and 5 are best to define cases of dizygotic twin pregnancies where one of the embryos has changed neoplastically. Unfortunately, most molar afterbirths, concomitant with a living fetus, described so far did not undergo a chromosomal analysis. Thus, an initially multiple pregnancy cannot be excluded when only minute molar lesions are revealed in a placenta.

The most effective way to diagnose gestational trophoblastic disease is sonography $[16,68]$. The image is very characteristic and looks like "blizzard". Yet, mole concomitant with a living fetus or fetuses often happens to be unrecognized during pregnancy. It is not diagnosed before a postpartum examination. Such diagnostic delays may be due to the fact that the sonographist does not realize that such a concurrence is at all possible, 
especially that a living fetus concomitant with a mole is rather rare. It is particularly difficult to diagnose partial mole. When there are only small pathological changes in a placenta, high resolution equipment has to be used to make them visible. In other cases, when the number of fetal elements is very small, it may be very difficult to differentiate them from complete mole. It is possible to recognize molar degeneration of villi only in a postpartum microscopic examination of the afterbirth.

In the differential sonographic diagnostics one has to assume a living fetus may be concurrent with:

1. uterine myomas [especially those undergoing necrosis];

2. "empty" fetal ovum;

3. intrauterinely necrotic fetal ovum;

4. extravasated, coagulated blood;

5. additional placental lobe;

6. placental haemangioma.

Until recently, trophoblastic tumours were differentiated only basing on a histological examination. A cytogenetic analysis seems jest as important. It enables particular kinds of mole to be differentiated from one another precisely. Consequently, it makes it possible to determine early the feasibility of a malignant transformation.

Table 1

\begin{tabular}{|c|c|c|c|c|}
\hline Kind of pathology & $\begin{array}{c}\text { Elements of } \\
\text { fetus and afterbirth }\end{array}$ & Karyotype & $\begin{array}{c}\text { Nuclear } \\
\text { genetic material }\end{array}$ & $\begin{array}{l}\text { Malignant } \\
\text { transformation }\end{array}$ \\
\hline $\begin{array}{l}\text { Molar degeneration } \\
\text { of villi }\end{array}$ & present & $\begin{array}{c}46, X X \text { or } \\
46, X Y\end{array}$ & $\begin{array}{l}\text { from both } \\
\text { parents }\end{array}$ & absent \\
\hline $\begin{array}{l}\text { Partial hydatid } \\
\text { mole }\end{array}$ & present & $\begin{array}{l}\text { mostly polyploid } \\
69, \mathrm{XXX}\end{array}$ & $\begin{array}{l}\text { paternal } \\
\text { prevalence }\end{array}$ & doubtful \\
\hline $\begin{array}{l}\text { Complete hydatid } \\
\text { mole }\end{array}$ & absent & $\begin{array}{l}\text { diploid } 46, X X \text {, less } \\
\text { often } 46, X Y\end{array}$ & paternal & $\begin{array}{c}46, \mathrm{XX} \text { in } 20 \% \\
46, \mathrm{XY} \text { in } 40-60 \%\end{array}$ \\
\hline Choriocarcinoma & absent & $\begin{array}{c}\text { diploid } \\
\text { often pathological }\end{array}$ & paternal & malignant tumor \\
\hline
\end{tabular}

\section{REFERENCES}

1. Azume Ch et al.: Am J Obstet Gynecol, 1992, 166, 664.

2. Bagshawe KD: Cancer, 1976, 38, 1373.

3. Bagshawe KD et al.: Lancet, 1990, 1, 1074.

4. Baldwin VJ: Pathology of Multiple Pregnancy. Blackwell Scientific Publications, Boston 1991, 221.

5. Barton SC et al.: Nature 1984, 311, 374. 
6. Beischer NA: Aust $\mathrm{n}$ ZJ Obstet Gynecol, 1966, 6, 127.

7. Benson PF et al.: Br Med J 1962, 1, 841.

8. Blackburn GK: J Pediatr, 1976, 89, 680.

9. Blickstein J, Borenstein R: Acta Genet Med Gemellol, 1989, 38, 279.

10. Bracken MB et al.: Epidemiol Rev, 1984, 6, 52.

11. Brewer JI, Mazur MT: Am J Surg Pathol, 1981, 5, 167.

12. Carlson JA Jr et al.: Gynecol Oncol, 1984, 17, 241.

13. Daamen CBF et al.: J Obstet Gynaecol Br Emp, 1961, 68, 144.

14. Davis JR: Cancer Genet Cytogenet, 1986, 19, 123.

15. De George FV: Am J Obstet Gynecol, 1970, 108, 369.

16. Dodson MG: J Reprod Med, 1983, 28, 741.

17. Doshi N et al:: Hum Pathol, 1983, 14, 716.

18. Driscoll SG: Obstet Gynecol, 1963, 21, 96.

19. Driscoll SG: Lab Inwest, 1983, 48, 21 A.

20. EdwardsYH et al.: Ann Hum Genet 1984, 48, 119.

21. Feinberg RF et al.: Obstet Gynecol, 1988, 72, 485.

22. Feldmann K: N Engl J Med, 1977, 296, 880.

23. Fisher RA et al.: Br Med J, 1982, 284, 1218.

24. Fisher RA et al.: Br J Obstet Gynaecol, 1984, 91, 690.

25. Fisher RA et al.: Br J cancer, 1988, 58, 788.

26. Hertz R: Ann NY Scad Sci, 1971, 172, 279.

27. Hohe PT et al.: Obstet Gynecol, 1971, 38, 899.

28. Jacobs PA et al.: Nature, 1980, 286, 714.

29. Jacobs PA et al.: Ann Hum Genet 1982, 46, 223.

30. Jones WB: Am J Obstet Gynecol, 1990, 162, 1286.

31. Jones WB, Lauersen NH: Am J Obstet Gynecol, 1975, 122, 267.

32. Kajii T, Ohama K: Nature, 1977, 268, 633.

33. Kajii T et al.: Am J Obstet Gynecol, 1984, 150, 57.

34. Ko TM et al.: Am J Obstet Gynecol, 1991, 164, 901.

35. Kruseman AC et al.: Am J Clin Pathol, 1977, 67, 279.

36. La Vecchia C et al.: Obstet Gynecol, 1982, 60, 250.

37. Lawler SD et al.: Lancet, 1979 2, 580.

38. Lawler SD et al.: Cancer Genet Cytogenet, 1982, 5, 309.

39. Lawler SD, Fisher RA: Placenta, 1987, 8, 77.

40. Lawler SD et al.: Am J Obstet Gynecol, 1991, 164, 1270.

41. Miller JM Jr et al.: Obstet Gynecol, 1979, 53, 207.

42. Nobunaga T et al.: Am J Obstet Gynecol, 1990, 163, 634.

43. Ober WFass OS: J Hist Med, 1961, 16, 49.

44. Ohmichi M et al.: Acta Obstet Gynecol Scand, 1986, 65, 523.

45. Olive DL et al.: Am J Obstet Gynecol, 1984, 148, 711.

46. Osada H et al.: Am J Obstet Gynecol, 1991, 165, 682.

47. Pattillo RA et al.: Am J Obstet Gynecol, 1981, 141, 104.

48. Pisarski T, Dydowicz M: Ann Med Soc Pol Acad Sc, 1970, 14, 297.

49. Poen HT, Djojopranoto M: Am J Obstet Gynecol, 1965, 92, 510.

50. Rather LJ, Pare A: Bull NY Aca Med, 1971, 47, 508.

51. Saldana LR et al.: Am J Obstet Gynecol, 1987, 157, 712.

52. Santamaria M et al.: Pediatric Pathology, 1987, 7, 601.

53. Sauerbrei EE et al.: Radiology, 1980, 135, 415.

54. Sheppard DM et al.: Hum Genet, 1982, 62, 371.

55. Sheppard DM et al.: Cancer Genet Cytogenet, 1985, 16, 251.

56. Shiina Y, Ichinoe K: Acta Obstet Gynecol Jpn, 1979, 31, 82. 


\section{W. Malinowski et al.}

57. Surani MAH et al.: Nature $1984,308,648$.

58. Surti U et al.: Am J Obstet Gynecol, 1982, 144, 84.

59. Suzuki M et al.: Obstet Gynecol, 1980, 56, 384.

60. Szulman AE, Surti U, : Am J Obstet Gynecol, 1978, 132, 22.

61. Szulman AE et al.: Hum Pathol, 1981, 12, 1016.

62. Toth A et al.: Gynecol Obstet Invest, 1992, 33, 153.

63. Wake $\mathrm{N}$ et al.: Cancer Res, 1981, 41, 3137.

64. Wallace DC et al.: Hum Genet, 1982, 61, 145.

65. Vassilakos P, Kajii T, Lancet, 1976, 1, 259.

66. Vassilakos P et al.: Am J Obstet Gynecol, 1977, 127, 167.

67. Witzleben CL, Bruninga G: J Pediatr, 1968, 73, 374.

68. Woo JSK et al.: J Ultrasound Med, 1983, 2, 261.

69. Yamashita K et al.: Am J Obstet Gynecol, 1979, 135, 597.

70. Yuen BH et al.: Am J Obstet Gynecol, 1981, 139, 316.

Correspondent: W. Malinowski, Kutno Hospital, Kutno, Poland. 